\title{
Enhancing trans-resveratrol topical delivery and photostability through entrapment in chitosan/gum Arabic Pickering emulsions
}

\author{
Asma Sharkawy a ${ }^{a}$, Filipa M. Casimiro ${ }^{a}$, Maria Filomena Barreiro b,c,*, Alírio E. Rodrigues ${ }^{\mathrm{a}, * *}$

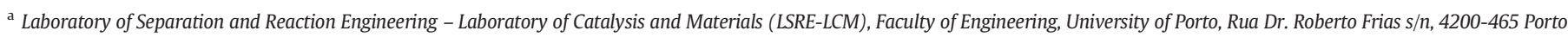 \\ Portugal

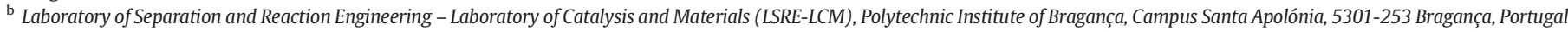 \\ c Centro de Investigação de Montanha (CIMO), Instituto Politécnico de Bragança, Campus de Santa Apolónia, 5300-253 Bragança, Portugal
}

\section{A R T I C L E I N F O}

\section{Article history:}

Received 16 November 2019

Received in revised form 5 January 2020

Accepted 6 January 2020

Available online 7 January 2020

\section{Keywords:}

Resveratrol

Pickering emulsions

Chitosan/gum Arabic nanoparticles

Topical delivery

Photostability

Biodegradable

\begin{abstract}
A B S T R A C T
The surfactant-free nature and higher stability of Pickering emulsions make them preferable solutions over conventional emulsions for skin applications. In this work, Pickering emulsions stabilized by chitosan/gum Arabic $(\mathrm{CH} / \mathrm{GA})$ nanoparticles were tested as vehicles for trans-resveratrol topical delivery. Skin absorption was examined ex vivo using Franz diffusion cells and porcine skin. Pickering emulsions allowed higher cutaneous retention and lower permeation of resveratrol, in comparison with a control solution based on a $20 \% \mathrm{v} / \mathrm{v}$ ethanol. The total amount of resveratrol retained in the skin, $24 \mathrm{~h}$ after the application, was $11.60 \%$ and $10.82 \%$ of the applied dose for the tested Pickering emulsion-based formulations prepared with $0.5 \%$ and $1.5 \% \mathrm{w} / \mathrm{v} \mathrm{CH} / \mathrm{GA}$ nanoparticles, respectively. In contrast, resveratrol skin retention from the control solution was only $2.86 \%$. Confocal laser scanning microscopy revealed enhanced skin deposition of Nile Red to deeper layers from the Pickering emulsionbased formulations. Moreover, Pickering emulsions led to trans-resveratrol photostability increase, as measured after exposure to UV for $4 \mathrm{~h}$. These results show that the $\mathrm{CH} / \mathrm{GA}$ Pickering emulsions are promising solutions for the topical delivery of trans-resveratrol and have the potential to be used as green cosmetic products.
\end{abstract}

(c) 2020 Elsevier B.V. All rights reserved.

\section{Introduction}

Research recognition has recently been given to natural-based cosmetics to overcome the side effects and toxicity related issues of synthetic ingredients in cosmetics and skincare products. Furthermore, there has been an increasing commitment from the cosmetic and pharmaceutical industry sectors to adopt green chemistry principles and to meet the consumers' demands for healthier and safer products, thus moving towards embracing Corporate Social Responsibility (CSR) by prioritizing respect for the environment and biodiversity, and giving back to the community [1]. Thus, the market for green cosmetics is quickly growing as these environmental and consumers' demands are rising competitive advantages [2]. This can be corroborated by the increasing dependence of the cosmetic industry on renewable plant/animal ingredients, which are

\footnotetext{
* Correspondence to: Maria Filomena Barreiro, Laboratory of Separation and Reaction Engineering - Laboratory of Catalysis and Materials (LSRE-LCM), Polytechnic Institute of Bragança, Campus Santa Apolónia, 5301-253 Bragança, Portugal.

** Correspondence to: Alírio E. Rodrigues, Laboratory of Separation and Reaction Engineering - Laboratory of Catalysis and Materials (LSRE-LCM), Faculty of Engineering, University of Porto, Rua Dr. Roberto Frias s/n, 4200-465 Porto, Portugal

E-mail addresses: barreiro@ipb.pt (M.F. Barreiro), arodrig@fe.up.pt (A.E. Rodrigues).
}

gradually substituting petrochemical ones and reinforcing the renewable carbon content in the final product [1].

Pickering emulsions are emulsions stabilized by solid particles instead of the classical surfactants [3]. The surfactant-free nature of Pickering emulsions makes them an emerging choice for topical formulations to overcome the adverse effects exhibited by the chemically synthesized emulsifiers on the skin (such as irritation and eczema), and on the environment $[3,4]$. The majority of the research conducted on Pickering emulsions for topical application reported the use of inorganic particles as stabilizers, such as silica and $\mathrm{TiO}_{2}$ [5]. However, at present, the use of organic and biopolymeric particles as Pickering stabilizers has acquired relevance over the synthetic and inorganic particles due to their sustainable and biocompatible character [5-8].

Chitosan is a polysaccharide obtained from the deacetylation of chitin, which is a natural polymer present in the exoskeleton of crustaceans. Chitin is insoluble in aqueous solutions, whereas chitosan is soluble in acidic media [9]. Chitosan has been reported to have skin moisturizing, humectant, antioxidant, anti-inflammatory and UV protective properties $[9,10]$. Gum Arabic is a natural polysaccharide obtained from Acacia tree that, according to in vitro studies, is able to protect the skin against lipid peroxidation caused by the continuous 
exposure to UV light, and guard against premature skin aging [11]. Despite these skin benefits, the use of gum Arabic in Pickering emulsion formulations has been only recently reported in very few studies that focused on food applications.

Resveratrol is a plant polyphenol with diverse therapeutic and prophylactic properties. It has been reported to have anti-inflammatory, antimicrobial, chemopreventive and strong antioxidant activities [12-14]. Studies have shown that it protects the skin against aging by neutralizing pro-oxidant species directly, as well as by stimulating endogenous antioxidant defense pathways in the skin [12]. It has been also demonstrated that it positively affects the expression of specific genes in human skin, in a way that stimulates the production of collagen and elastin, and hence, enhances skin elasticity and thickness, and reduces wrinkles [15]. Resveratrol has poor water solubility and exists in the "cis" or "trans" configuration, with the trans form reported to have higher biological activity than the cis form. However, the trans form is photosensitive and transforms into the cis form when exposed to direct sunlight or UV radiation $[12,14]$. To enhance the solubility and stability of resveratrol, and to leverage the previously mentioned biological potentials, its encapsulation in different systems designed for topical delivery, such as liposomes, lipid nanoparticles and emulsions has been tested [16-18].

The use of Pickering emulsions as vehicles of hydrophobic drugs has been recently studied aiming at enhancing the absorption and bioavailability of the active agents $[19,20]$. In what concerns resveratrol, the examples involving the use of Pickering emulsions are scarce. Matos et al. [21] developed resveratrol-loaded Pickering emulsions stabilized by modified quinoa starch particles. Also, Zhang et al. [22] encapsulated resveratrol in Pickering emulsions stabilized by zein/chitosan particles, proving higher stability and better sustained release of resveratrol in comparison with nanoemulsions developed in the same study. These resveratrol-loaded Pickering systems focused only on food applications, and no studies to date examined resveratrol entrapment in Pickering emulsions for skin applications.

In a recent study, our research group developed biopolymeric chitosan/gum Arabic nanoparticles with near-neutral wettability and successfully used these nanoparticles to produce novel biodegradable o/w Pickering emulsions, which have presented high storage stability and excellent rheological properties for cosmetic applications [23]. Following these advancements, the main objective of the present work is to investigate the potential use of Pickering emulsions stabilized with chitosan/ gum Arabic nanoparticles as novel surfactant-free delivery vehicles for the topical application of trans-resveratrol. Moreover, the work also aims to examine the ability of the developed biopolymeric-based Pickering emulsions to protect trans-resveratrol against UV degradation. To the best of our knowledge, this is the first study that investigates the use of Pickering emulsions for the topical delivery of resveratrol.

\section{Materials and methods}

\subsection{Materials}

Chitosan (ChitoClear ${ }^{\circledR}$ ) with a degree of deacetylation of 96\% and MW of 100-200 kDa was a kind gift from Primex ehf, Iceland. Gum Arabic, olive oil (highly refined, low acidity), trans-resveratrol (grade $\geq 99 \%$ ), Tween $20 \circledR$ and Nile Red were purchased from Sigma Aldrich. Methanol and formic acid (gradient grade for HPLC) were supplied by Merck. Ethanol and acetic acid $(0.1 \mathrm{~N})$ were purchased from Carlo Erba Reagents and Alfa Aesar, respectively. The porcine skin was obtained from pig ears which were supplied by a local slaughterhouse in Portugal.

\subsection{Methods}

\subsubsection{Preparation of chitosan/gum Arabic ( $C H / G A)$ nanoparticles and Pick- ering emulsions}

The nanoparticles were prepared through ionotropic gelation following a method developed in our research group [23]. Briefly, $\mathrm{CH} / \mathrm{GA}$ nanoparticles (with 1:1 weight ratio) were prepared at two different concentrations, namely $0.5 \%$ and $1.5 \% \mathrm{w} / \mathrm{v}$. The nanoparticle dispersions were obtained by dissolving the required amount of chitosan in $50 \mathrm{ml}$ of $0.1 \mathrm{~N}$ acetic acid, followed by the dropwise addition of the corresponding weight of gum Arabic dissolved in $50 \mathrm{ml}$ of deionized water. The addition was done under continuous magnetic stirring at $800 \mathrm{rpm}$ for $30 \mathrm{~min}$. The final $\mathrm{pH}$ of the dispersions was maintained at 4 .

$\mathrm{CH} / \mathrm{GA}$ nanoparticles stabilized Pickering emulsions were prepared by slowly adding the olive oil to the nanoparticle dispersions. The process was conducted under continuous homogenization (using Ultraturrax DI 25 basic IKA) at a speed of 13,500 rpm for 5-7 min. Pickering emulsions were prepared using the two produced $\mathrm{CH} / \mathrm{GA}$ nanoparticles dispersions (with concentrations $0.5 \%$ and $1.5 \% \mathrm{w} / \mathrm{v}$ ), and a constant oil volume fraction $(\varphi=0.6)$. The total volume of the formed emulsions was $100 \mathrm{ml}$.

Resveratrol-loaded Pickering emulsions were prepared by incorporating trans-resveratrol in the used olive oil phase. The dissolution was aided by applying ultrasonication for $30 \mathrm{~min}$, avoiding light exposure during this step. Then, the emulsions were prepared as previously described. Resveratrol concentration in the prepared emulsions was $0.1 \% \mathrm{w} / \mathrm{v}$ (100 $\mathrm{mg}$ in $100 \mathrm{ml}$ total emulsion volume). The emulsions were prepared using $0.5 \%$ and $1.5 \% \mathrm{w} / \mathrm{v} \mathrm{CH} / \mathrm{GA}$ nanoparticles to assess the effect of low and high nanoparticles concentration on resveratrol skin uptake and photostability.

\subsubsection{Characterization of the $\mathrm{CH} / \mathrm{GA}$ nanoparticles and Pickering emulsions}

Transmission electron microscopy (TEM) was used to examine the morphology of the produced nanoparticles. The freshly prepared nanoparticles dispersion (prepared with a concentration of $1.5 \% \mathrm{w} / \mathrm{v}$ ) was mounted on Formvar/carbon film-coated mesh nickel grids (Electron Microscopy Sciences, Hatfield, PA, USA). Visualization was conducted by a JEOL JEM 1400 TEM at $120 \mathrm{kV}$ (Tokyo, Japan), and the images were acquired using a CCD digital camera Orious 1100 W (Tokyo, Japan).

The average size of the formed nanoparticles was measured by dynamic light scattering (DLS) using a Zetasizer Nano ZS ZEN3600 (Malvern Instruments, UK). The sample was diluted to 100 -fold with deionized water (serial dilution). The results were reported as the average of three consecutive readings.

The dynamic interfacial tension between $\mathrm{CH} / \mathrm{GA}$ nanoparticles dispersions (with concentrations of $0.1 \%, 0.5 \%$ and $1.5 \% \mathrm{w} / \mathrm{v}$ ) and olive oil was determined as a function of time (over $4000 \mathrm{~s}$ ). The test was conducted using a Dataphysics OCA15 Plus device (Dataphysics, Germany), by forming a drop of the $\mathrm{CH} / \mathrm{GA}$ nanoparticles dispersion inside a cuvette filled with olive oil with a submerged syringe tip. The interfacial tension was calculated by the pendant drop shape with YoungLaplace equation. The measurements were performed at room temperature $\left(25^{\circ} \mathrm{C}\right)$.

The interfacial structure of $\mathrm{CH} / \mathrm{GA}$ nanoparticles-stabilized Pickering emulsions was visualized by a cryo-scanning electron microscope (JEOL JSM 6301F/Oxford INCA Energy 350/Gatan Alto 2500). This characterization was performed for the formulations prepared with nanoparticles with a concentration of $1.5 \% \mathrm{w} / \mathrm{v}$ (with and without resveratrol). Briefly, the specimen was rapidly cooled by plunging it into sub-cooled nitrogen (slush nitrogen) and transferred under vacuum to the cold stage of the preparation chamber. The specimen was fractured, sublimated for $60 \mathrm{~s}$ at $-90{ }^{\circ} \mathrm{C}$, and coated with $\mathrm{Au} / \mathrm{Pd}$ by sputtering for $50 \mathrm{~s}$. The sample was then transferred into the SEM chamber. The sample was analyzed at a temperature of $-150{ }^{\circ} \mathrm{C}$, and the images were taken at different magnifications $(10,000 \times$ and $20,000 \times)$.

Morphology comparison of the resveratrol-loaded Pickering emulsions prepared with $0.5 \%$ and $1.5 \% \mathrm{w} / \mathrm{v}$ nanoparticle concentrations was examined by optical microscopy using a Leica DM 2000 optical microscope. The average droplet size was measured using a laser diffraction particle size analyzer (LS 230, Beckman Coulter). The refractive indexes for the water and the oil phase were 1.33 and 1.46 , respectively. 
The morphology and the average droplet size were examined for the freshly prepared resveratrol-loaded Pickering formulations and after storage for 2 months at room temperature.

\subsubsection{Resveratrol encapsulation efficiency}

The encapsulation efficiency (EE \%) was determined to assess the amount of resveratrol retained in the core oil droplets and know its distribution between the oil and aqueous phases of the Pickering emulsion. It was conducted by accelerated phase separation achieved by centrifugation in accordance with a previously reported method, but with slight modifications [24]. Briefly, $1 \mathrm{ml}$ of the Pickering emulsion was diluted with $10 \mathrm{ml}$ of methanol and placed in a sonication bath for $10 \mathrm{~min}$ in order to de-emulsify the formed emulsion and extract the total resveratrol (RSV) amount. Thereafter the sample was filtered through a $0.2 \mu \mathrm{m}$ nylon syringe filter, and RSV concentration (Total RSV) was determined by HPLC (as described in Section 2.2.8). Additionally, another $1 \mathrm{ml}$ of the Pickering emulsion was centrifuged at $10000 \mathrm{rpm}$ for $15 \mathrm{~min}$. The obtained serum layer, which represents the aqueous phase, was collected, filtered, and analyzed by HPLC for RSV quantification (Free RSV). $\mathrm{EE} \%$ was then calculated by the following equation:

$E E \%=\frac{\text { Total RSV }- \text { Free RSV }}{\text { Total RSV }}$

\subsubsection{In-vitro release studies}

Resveratrol release was studied using jacketed Franz diffusion cells (PermeGear, USA) with an effective diffusion area of $0.64 \mathrm{~cm}^{2}$ (contact area between donor and receptor compartments), and a receptor chamber volume of $5 \mathrm{ml}$. A schematic representation is provided in Fig. 1. A cellulose acetate membrane with a pore size of $0.2 \mu \mathrm{m}$ (Sartorius Stedim Biotech $\mathrm{GmbH}$, Germany), placed between the donor compartment and the receptor compartment, was used. The receptor chamber contained an ethanol/water solution (1:1) containing $5 \mathrm{~g} / \mathrm{L}$ of Tween 20®; to ensure sink conditions during the experiment period [25]. The receptor medium was kept under magnetic stirring at $600 \mathrm{rpm}$, and the temperature was maintained at $32{ }^{\circ} \mathrm{C}$ using a thermostatic water bath. The donor chamber was filled with $300 \mu \mathrm{l}$ of the Pickering emulsion sample or the RSV control solution (RSV in hydroalcoholic solution $(20 \% \mathrm{v} / \mathrm{v}$ ethanol)). Both samples contained an equivalent amount of RSV $(1 \mathrm{mg} / \mathrm{ml})$. At predefined time intervals, $400 \mu \mathrm{l}$ of the receptor fluid was withdrawn and immediately replaced by an equal volume of fresh receptor fluid medium. All the assays were conducted in triplicate. The collected samples were then characterized by HPLC for RSV quantification. The cumulative RSV release \% was calculated by the following equation [26]:

Cumulative $R S V$ release $\%=\frac{\text { Amount of } R S V \text { released at time } t}{\text { Total amount of encapsulated } R S V} * 100$

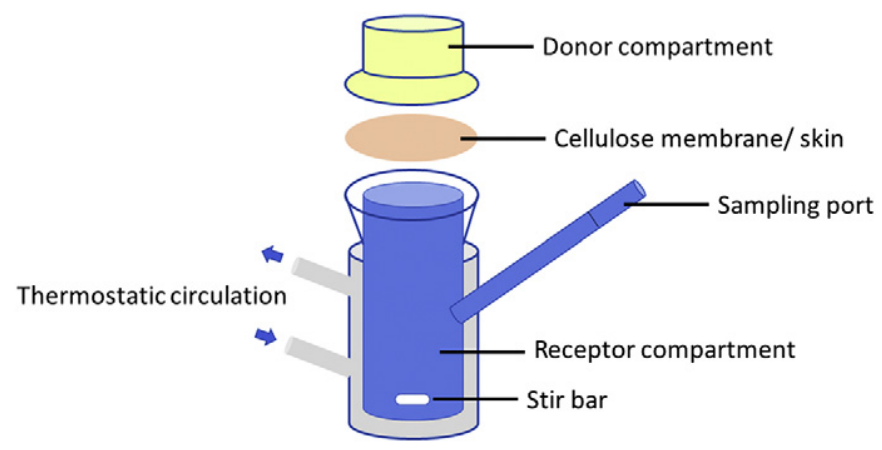

Fig. 1. Schematic representation of Franz diffusion cell.

\subsubsection{Ex-vivo skin retention and permeation studies}

Resveratrol skin absorption and permeation were evaluated using porcine ear skin mounted in the previously described Franz diffusion cells, according to the OECD guidelines [27]. The full-thickness skin was excised, and the hair was shaved off with a razor. The subcutaneous fat and hypodermis tissue were removed with forceps and surgical scissors. The skin membrane was placed with the stratum corneum side facing the donor compartment and the dermis facing the receptor medium compartment. The receptor medium (ethanol and water solution (1:1) and Tween $20 \AA(5 \mathrm{~g} / \mathrm{L}))$ was kept under magnetic stirring at $600 \mathrm{rpm}$ at $32 \pm 1{ }^{\circ} \mathrm{C}$. For the assays, $300 \mu \mathrm{l}$ of the Pickering emulsion, or of the control sample (RSV in $20 \% \mathrm{v} / \mathrm{v}$ ethanol) was added to the donor chamber and uniformly spread over the skin. The concentration of RSV in the control sample was the same as in the tested Pickering formulations (i.e., $0.1 \% \mathrm{w} / \mathrm{v}$ ). The experiment was performed under occlusive conditions by covering the donor chambers with Parafilm ${ }^{\circledR}$ to avoid water evaporation. Aliquots of $400 \mu \mathrm{l}$ were collected from the receptor fluid at predetermined time intervals $(0,2,4,6,8$ and $24 \mathrm{~h})$ to quantify the permeated resveratrol. The collected volume was replaced by an equal volume of fresh receptor medium to keep sink conditions. The collected samples were protected from light to avoid RSV degradation and isomerization before quantification by HPLC.

Total mass recovery of RSV was checked by considering the mass balance of RSV distributed among the skin, and the donor and receptor compartments $[7,28]$. At the end of the assay, the Franz diffusion cells were disassembled, and the residual Pickering emulsion (or control sample) in the donor compartment was diluted with $30 \mathrm{ml}$ of fresh receptor fluid solution. Moreover, the skin surface was washed with $10 \mathrm{ml}$ of fresh receptor fluid, then the resulting washing solution was added to the previously obtained solution. This final solution was then filtered and analyzed by HPLC for RSV quantification. Afterwards, the skin was dried with a wipe, and then stripping was done using Scotch ${ }^{\circledR}$ Crystal adhesive tape (3M, Minnesota, USA). Eighteen tape-stripping were applied consecutively to remove the stratum corneum. The tapes were collected, cut into small pieces, added to $40 \mathrm{ml}$ of methanol in a sealed glass bottle and placed in an ultrasonic water bath for 30 min to extract RSV from the removed stratum corneum. The extraction liquid was then filtered and analyzed by HPLC to quantify RSV. The remaining skin membrane consisting of the viable epidermis and dermis (VED), was first cut into small pieces, then put in $40 \mathrm{ml}$ of methanol and placed in an ultrasonic water bath for $1 \mathrm{~h}$ to extract RSV. The sample was then filtered and analyzed by HPLC. All the samples were protected from light to prevent RSV degradation. Each test was performed, at least, in triplicate $(n \geq 3)$. This mass balance is important to validate the performed studies.

\subsubsection{Examination of skin retention by confocal laser scanning microscopy (CLSM) \\ CLSM was used to visualize the retention and distribution in the skin} layers by using Nile Red as a fluorescent probe. This procedure has become a well-recognized technique to detect the distribution of hydrophobic drugs in the different skin layers $[7,29]$. The Pickering emulsion formulations were prepared using $0.01 \% \mathrm{w} / \mathrm{v}$ of Nile Red (instead of RSV) following the base procedure described in Section 2.2.1. The control sample was prepared by dissolving the same amount of Nile Red in deionized water. The assay was performed by applying $300 \mu$ of the Pickering emulsion (or the control sample) on the porcine skin in the Franz cells, as described in Section 2.2.5. After $6 \mathrm{~h}$, the skin samples were removed and washed thoroughly with deionized water and phosphate buffer solution to remove any excess of undiffused Nile Red. The skin samples were placed in tissue freezing medium and frozen overnight at $-20^{\circ} \mathrm{C}$. On the second day, the samples were cryo-sectioned by a cryostat (Cryostat Leica CM 3050S) to skin sections with a thickness of $16 \mu \mathrm{m}$. The sections were covered by a drop of mounting medium and glass coverslips, and visualized using a Leica TCS-SP5 AOBS confocal microscope (Leica Microsystem Inc., Germany) at an excitation wavelength of $561 \mathrm{~nm}$ and emission wavelengths of $570 \mathrm{~nm}$ and $691 \mathrm{~nm}$. 


\subsubsection{Photostability of resveratrol}

The photostability studies were conducted following the method of Khan et al. [30], with some modifications. Resveratrol-loaded Pickering emulsion formulations prepared with $0.5 \%$ and $1.5 \%(\mathrm{w} / \mathrm{v}$ ) $\mathrm{CH} / \mathrm{GA}$ nanoparticle concentrations, and a control sample of RSV in methanol were exposed to UV light ( $365 \mathrm{~nm}$ ) using an HQ Power VDL $15 \mathrm{~W}$ ultraviolet lamp (Velleman ${ }^{\circledR}$, Belgium) for $4 \mathrm{~h} .15 \mathrm{ml}$ of each sample were placed in glass round plates (with a diameter of $6 \mathrm{~cm}$ ) and positioned $20 \mathrm{~cm}$ away from/below the lamp. Irradiated samples were collected after 0.5, 1, 2, 3 and $4 \mathrm{~h}$, and analyzed by HPLC for trans-resveratrol quantification.

\subsubsection{Resveratrol quantification}

Trans-resveratrol was quantified by high performance liquid chromatography (HPLC) using a reversed phase column ACE 5 C18pentafluorophenyl group ( $250 \mathrm{~mm} \times 3 \mathrm{~mm}, 5 \mu \mathrm{m})$. The eluents consisted of solution A (water/methanol: $95 \% / 5 \%(v / v)$ ) and solution B (water/methanol: 5\%/ 95\% (v/v)). Both solutions were acidified with $0.1 \%(\mathrm{v} / \mathrm{v})$ formic acid. The analysis was conducted at $30{ }^{\circ} \mathrm{C}$ using isocratic flow at a flowrate of $0.5 \mathrm{ml} / \mathrm{min}$, and UV detection at $306 \mathrm{~nm}$.

\section{Results and discussion}

\subsection{Characterization of the produced $\mathrm{CH} / \mathrm{GA}$ nanoparticles and Pickering emulsions}

TEM images (Fig. 2) show that the developed CH/GA nanoparticles are spherical, semi-spherical and oval. The irregular morphology of the nanoparticles is due to the absence of an oil core template for the deposition of the $\mathrm{CH} / \mathrm{GA}$ coacervates [23].

The obtained size distribution in number of the produced $\mathrm{CH} / \mathrm{GA}$ nanoparticles $(1.5 \% \mathrm{w} / \mathrm{v})$ is characterized by an average size of $109 \mathrm{~nm}$, and a polydispersity index (PDI) of 0.218 . Previous studies on this system indicated that only minor agglomeration occurred during storage [23].

The interfacial tension between $\mathrm{CH} / \mathrm{GA}$ nanoparticles and olive oil decreased with the increase in the concentration of the nanoparticles, as shown in Fig. 3. Moreover, it can be noted that the rate of this decrement was initially high but became slower after $1500 \mathrm{~s}$. This could be attributed to the penetration and initial adsorption of the nanoparticles at the oil-water interface leading to interfacial tension decrease. This phenomenon was followed by the packing and rearrangement of the nanoparticles at the interface. The saturation of the oil-water interface with nanoparticles decreases its ability to adsorb more particles, which subsequently led to a near-equilibrium state $[31,32]$. The results show that $\mathrm{CH} / \mathrm{GA}$ nanoparticles of higher concentrations $(0.5 \%$ and $1.5 \% \mathrm{w} /$

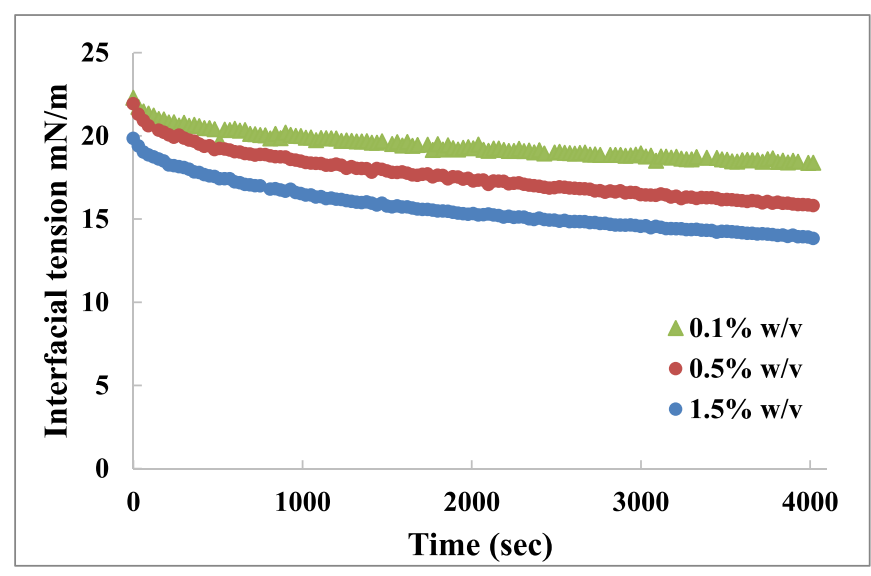

Fig. 3. Dynamic interfacial tension between $\mathrm{CH} / \mathrm{GA}$ nanoparticles with different concentrations $(0.1 \%, 0.5 \%$ and $1.5 \% \mathrm{w} / \mathrm{v})$ and olive oil versus time.

v) possess better emulsification properties in comparison to the nanoparticles of lower concentrations $(0.1 \% \mathrm{w} / \mathrm{v})$.

Cryo-SEM technique is currently applied to investigate the interfacial structure of emulsion systems, including Pickering emulsions. As can be observed from Fig. 4A, CH/GA nanoparticles form a dense layer around the oil droplet. The presence of such layer or sheath of nanoparticles, at the oil-water interface (i.e. around the oil core), results in the emulsion stabilization; as it provides steric hindrance and electrostatic repulsion that act against the coalescence of the droplets $[33,34]$. Fig. $4 \mathrm{~B}$ and $\mathrm{C}$ shows the surface of intact Pickering emulsion droplets, evidencing their rough and non-smooth appearance. At higher magnification (Fig. 4D), the surface reveals the presence of depressions or "dimpled-like" texture, similar to that of a golf ball surface. This might be explained by the irregular deposition and non-uniform stacking of the nanoparticles onto the droplet surface. Similar indentations and rough surfaces were reported for Pickering emulsions stabilized by zein/corn fiber gum colloidal particles [33] and zein/pectin nanoparticles [35].

Cryo-SEM images of the resveratrol-loaded Pickering emulsion (Fig. 4E and F) have shown that the emulsion droplets surface maintained its rough texture and possessed the same dimpled-like depressions observed in the base Pickering formulation (Pickering emulsion without RSV). This suggests that the incorporation of RSV did not influence the morphology and the deposition pattern of $\mathrm{CH} / \mathrm{GA}$ nanoparticles at the oil-water interface, indicating that the stability of the emulsion droplets against coalescence was not affected.

The optical microscopy images of freshly prepared RSV-loaded Pickering emulsions stabilized with $0.5 \% \mathrm{w} / \mathrm{v}$ and $1.5 \% \mathrm{w} / \mathrm{v} \mathrm{CH} / \mathrm{GA}$
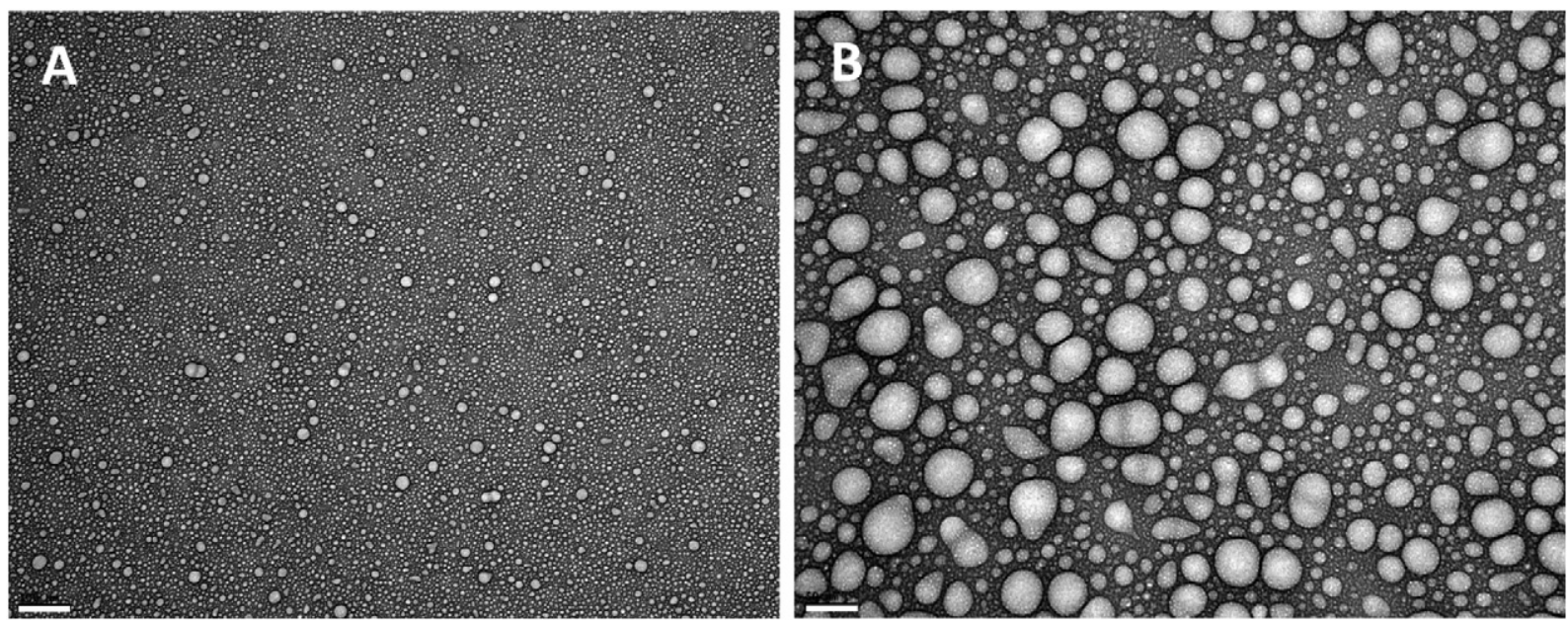

Fig. 2. TEM images of CH/GA nanoparticles (1.5\% w/v); Magnification A) 50,000×, scale bar: $100 \mathrm{~nm}$ and B) $200,000 \times$, scale bar: $50 \mathrm{~nm}$. 

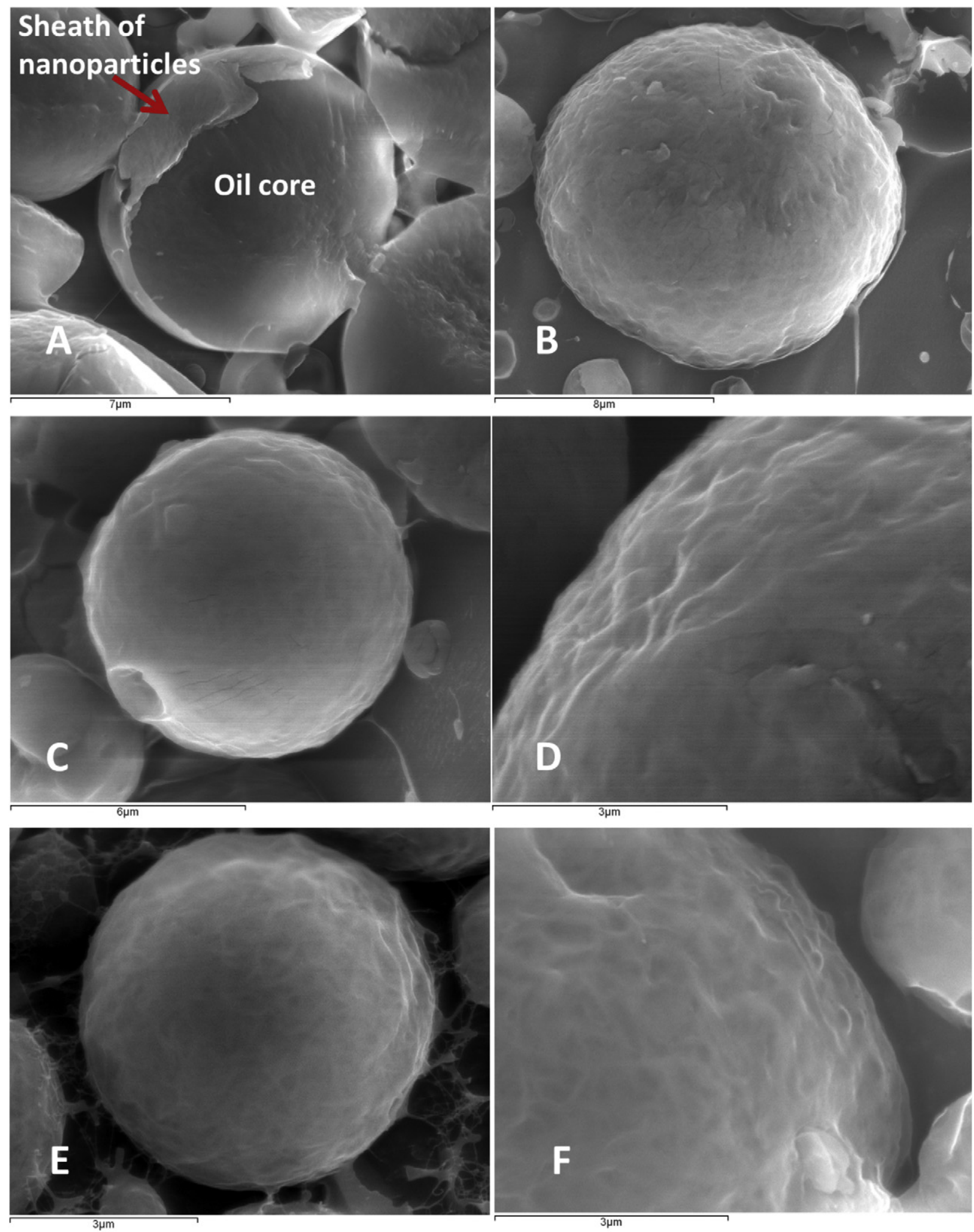

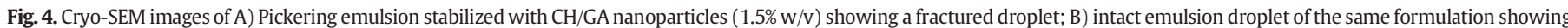

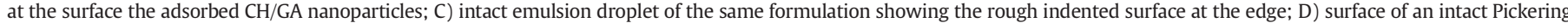

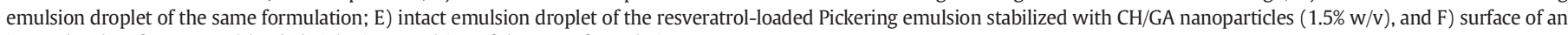
intact droplet of resveratrol-loaded Pickering emulsion of the same formulation.

nanoparticles are shown in Fig. 5A and C, respectively. The images show that the emulsion droplets possess well-defined spherical morphology for both concentrations. The droplet size distribution profiles of both formulations have shown a bimodal distribution (Fig. 6). It can be also observed that the size of the emulsion droplets decreased as the concentration of the nanoparticles increased, which is in accordance with the optical microscopy images (Fig. 5A and C). The optical microscope images of the two Pickering formulations after storage for two months at 

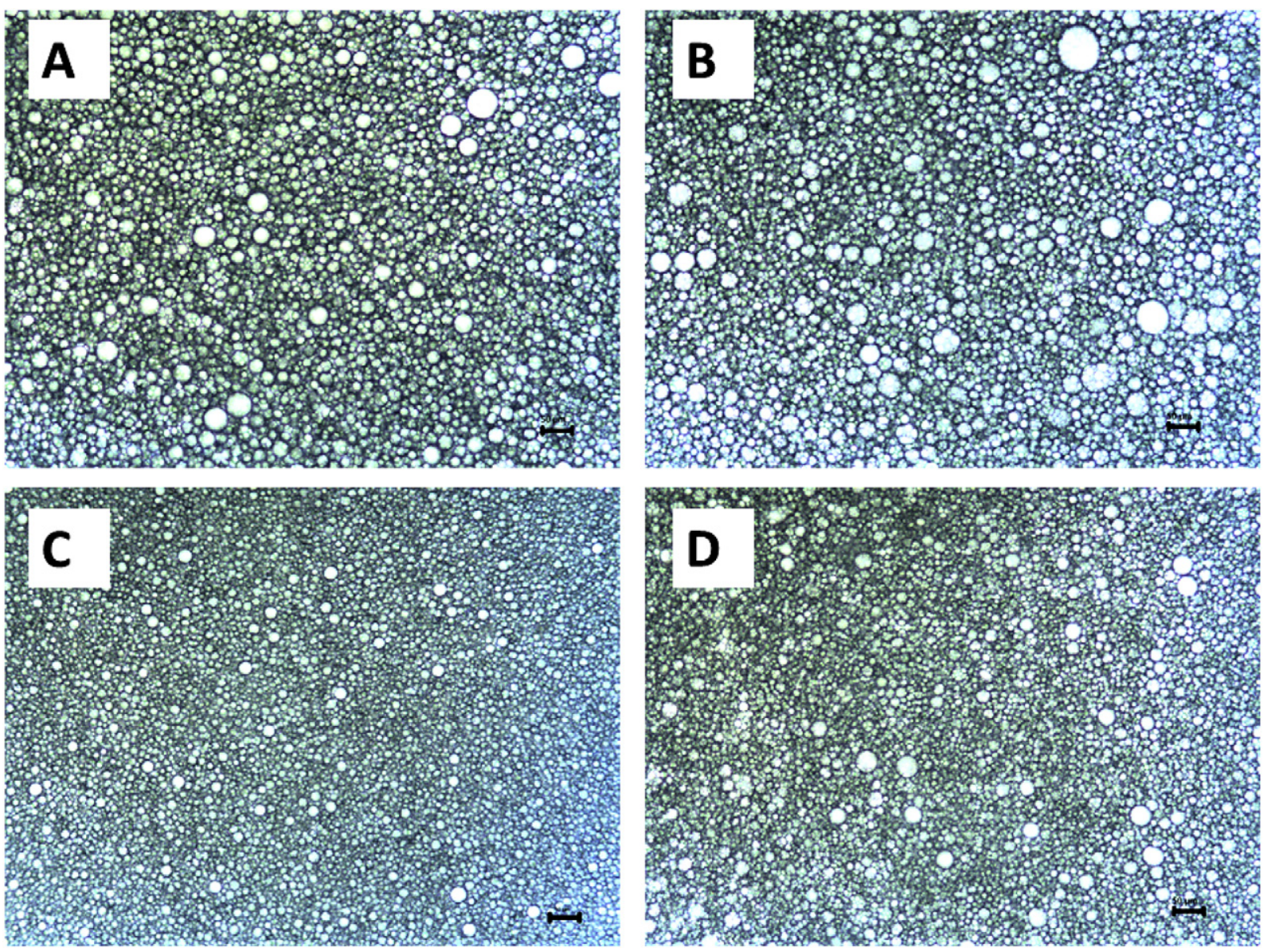

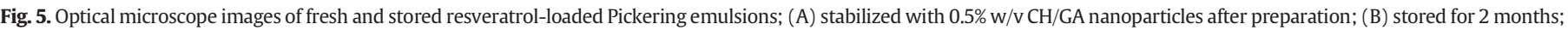
(C) stabilized with $1.5 \% \mathrm{w} / \mathrm{v} \mathrm{CH} / \mathrm{GA}$ nanoparticles after preparation; and (D) stored for 2 months. The scale bar corresponds to $50 \mu \mathrm{m}$.

room temperature (Fig. 5B and D) show that the emulsion droplets maintained their spherical morphology, and only a slight increase in the droplet size was observed.

Laser diffraction analysis has shown that the RSV-loaded Pickering formulation prepared with $0.5 \% \mathrm{w} / \mathrm{v} \mathrm{CH} / \mathrm{GA}$ nanoparticles has an average diameter of $23.98 \mu \mathrm{m}$, while the average diameter of the one prepared with $1.5 \% \mathrm{w} / \mathrm{v}$ is $17.11 \mu \mathrm{m}$. This is related to the fact that higher nanoparticle concentration causes the coverage of a larger interfacial area, thus decreasing the droplets size. After storage for 2 months, the average diameter was $30.47 \mu \mathrm{m}$ and $20.88 \mu \mathrm{m}$ for the formulations prepared with $0.5 \% \mathrm{w} / \mathrm{v}$ and $1.5 \% \mathrm{w} / \mathrm{v} \mathrm{CH} / \mathrm{GA}$ nanoparticles, respectively. These values are in agreement with what was observed previously by

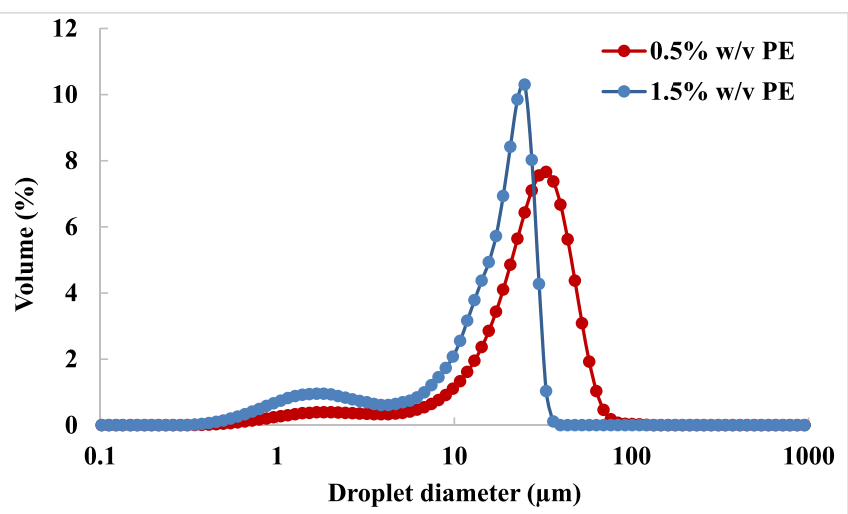

Fig. 6. Droplet size distribution profiles of RSV-loaded Pickering emulsions stabilized with $0.5 \%$ and $1.5 \% \mathrm{w} / \mathrm{v} \mathrm{CH} / \mathrm{GA}$ nanoparticles. optical microscopy, which pointed out for a minor coalescence of the droplets with time. Moreover, the values follow the pattern of our previous study concerning the development of the base Pickering emulsions (prepared without RSV) [23]. These base formulations maintained their stability for the studied period of two months.

The RSV encapsulation efficiency (EE\%) for the formulation prepared with $0.5 \% \mathrm{w} / \mathrm{v} \mathrm{CH} / \mathrm{GA}$ nanoparticles was $92.81 \% \pm 1.76$, whereas it was $94.50 \% \pm 0.23$ for the emulsion prepared with $1.5 \% \mathrm{w} / \mathrm{v} \mathrm{CH} / \mathrm{GA}$ nanoparticles. Similar high values of RSV encapsulation efficiency were reported for Pickering emulsions stabilized by octenyl succinic anhydride (OSA) modified starch particles [21]. In the present study, the slight difference in the values of $\mathrm{EE} \%$ of the two formulations demonstrates that the increase in the $\mathrm{CH} / \mathrm{GA}$ nanoparticle concentration had no influence on resveratrol retention. This suggests that the presence of the nanoparticles at a low concentration $(0.5 \% \mathrm{w} / \mathrm{v})$ was sufficient to form a mechanical barrier at the water-oil interface, which successfully achieved resveratrol entrapment in the oil phase.

\subsection{Resveratrol in vitro release and diffusion}

The release profiles of RSV from the Pickering emulsions prepared with $0.5 \%$ and $1.5 \% \mathrm{w} / \mathrm{v} \mathrm{CH} / \mathrm{GA}$ nanoparticles concentrations, and the control solution are shown in Fig. 7. It can be seen that after $24 \mathrm{~h}$, $53.7 \%$ of the total RSV was released from the Pickering formulation prepared with $0.5 \% \mathrm{w} / \mathrm{v} \mathrm{CH} / \mathrm{GA}$ nanoparticles, whereas only $38.5 \%$ was released from the formulation stabilized with $1.5 \% \mathrm{w} / \mathrm{v}$ nanoparticles. The slower release from the second formulation could be explained by the presence of a higher amount of nanoparticles. These particles being adsorbed at the emulsion oil droplet surfaces have eventually reduced the rate of RSV release from the oil core. 


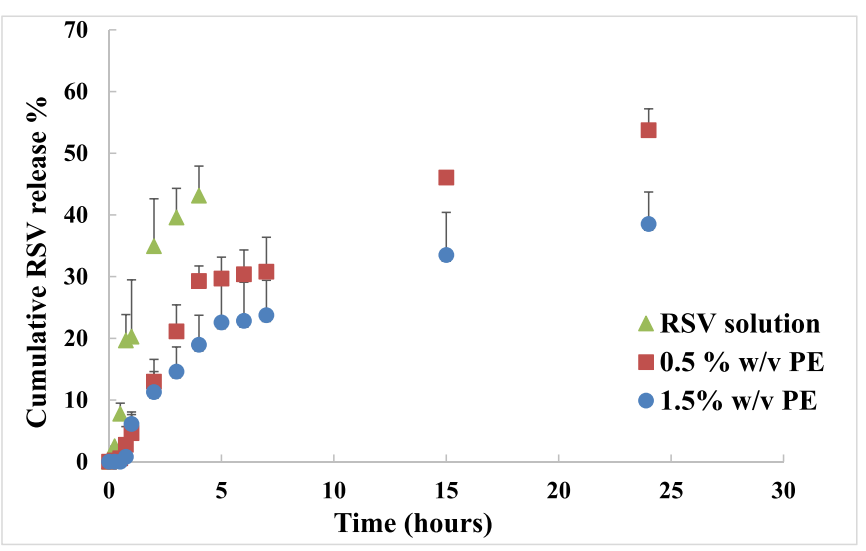

Fig. 7. In vitro RSV release profiles of Pickering emulsion formulations prepared with $0.5 \%$ $\mathrm{w} / \mathrm{v}$ and $1.5 \% \mathrm{w} / \mathrm{v} \mathrm{CH} / \mathrm{GA}$ nanoparticles, and RSV solution in diluted alcohol (20\% v/v) through cellulose acetate membrane.

The cumulative release profile of RSV from diluted ethanol was faster in the beginning (during the first $4 \mathrm{~h}$ ) reflecting the free passage of RSV through the cellulose acetate membrane. This behavior was expected along the entire test time, nevertheless, the experiment was discontinued after $4 \mathrm{~h}$ due to the drying of the vehicle and the membrane (despite of applying occlusive conditions; i.e. covering the donor compartment with Parafilm $\left.{ }^{\circledR}\right)$. Accordingly, the experimental points for the control solution represented in Fig. 7 only relate to the first $4 \mathrm{~h}$.

The release of an active agent from the Pickering emulsions is controlled by its ability to cross and diffuse through the nanoparticles shell covering the oil droplets. It is also dependent on its solubility and partition between the oil and aqueous phases of the emulsion [29]. Therefore, the slow release of RSV from Pickering emulsion formulations, in comparison with the control solution, could be explained based on RSV solubility difference in the aqueous and oil phases of the emulsion. The solubility of RSV in water is relatively low $(0.05 \mathrm{mg} / \mathrm{ml})$ compared to its solubility in the oil phase. Therefore, it is expected that RSV would be predominately distributed in the oil phase of the emulsion. This results in reducing the RSV release rate from the oil core, which subsequently decreases its passage through the membrane.

\subsection{Ex-vivo skin retention and permeation}

The stratum corneum which is the outermost layer of the skin is considered the main barrier for the permeation of the active agent. It consists of corneocytes fixed in an intercellular lipid matrix [36]. In the case of the topical route and cosmetics, it is important to enhance the permeation of the active agent through the stratum corneum in order to be retained in the other skin layers. The active agent should penetrate inner skin layers moderately, and not deeply to avoid reaching the blood circulation and making a systemic/therapeutic effect [37]. Avoiding systemic absorption is a crucial issue to enhance the skin benefits of the active agent intended for topical delivery $[5,8]$. Therefore, an efficient delivery of a cosmetic ingredient should achieve higher skin retention rather than permeation [38]. In general, the degree of skin penetration depends on the formulation, the chemical nature of the active compound and the skin hydration state [5]. It has been reported in previous studies that formulations with droplets smaller than $3 \mu \mathrm{m}$ penetrate the skin by diffusion and through the hair follicles, whereas formulations with sizes ranging from $3 \mu \mathrm{m}$ to $10 \mu \mathrm{m}$ penetrate through the hair follicles. Formulations with droplet sizes $>10 \mu \mathrm{m}$ tend to remain on the skin surface and the active agent eventually diffuses from them to the skin [8]. It is expected in the present study that the Pickering emulsion droplets would mainly remain on the skin, allowing RSV to diffuse through it with time.

As shown in Table 1 and Fig. 8, after 24 h of skin exposure to the Pickering formulations, only low amounts of RSV were detected in the receptor fluid. The percentage of the permeated RSV was $2.20 \%$ and $3.16 \%$ of the total applied dose, respectively for the Pickering emulsions stabilized by $0.5 \%$ and $1.5 \% \mathrm{w} / \mathrm{v} \mathrm{CH} / \mathrm{GA}$ nanoparticles. However, the skin absorption percentages were $11.60 \%$ and $10.82 \%$ of the total applied dose for Pickering emulsions stabilized by $0.5 \%$ and $1.5 \% \mathrm{w} / \mathrm{v} \mathrm{CH} / \mathrm{GA}$ nanoparticles, respectively. These results suggest that RSV-loaded Pickering emulsions retarded the diffusion of the RSV from the skin to the receptor fluid. In contrast, the control solution resulted in the permeation of a high amount of RSV through the skin (11.62\% of the total applied dose), suggesting its unsuitability as a cosmetic vehicle for RSV.

The concentration of RSV in the final preparation is restricted by its solubility in olive oil. In general, the solubility of RSV in oils is low [21]. The used strategy concerning the amount to be added to the formulation takes into consideration the dose of RSV required to achieve a cosmetic effect (for skin antioxidant activity), and the final dose that is successfully taken up by the skin. The reported results in the current study have shown relatively high skin uptake amounts of RSV in the viable epidermis and dermis (46.24-50.41 $\left.\mu \mathrm{g} / \mathrm{cm}^{2}\right)$, namely in comparison with other recent studies [12].

Pickering emulsions have been reported to enhance the permeation of hydrophilic drugs such as caffeine readily to the receptor compartment [39], while they favor the retention of lipophilic drugs in the stratum corneum [7,40]. CH/GA nanoparticles (with 1:1 weight ratio) are positively charged and have a zeta potential of $+56.3 \mathrm{mV}$ [23]. In this work, resveratrol showed a tendency towards higher retention in the viable epidermis and dermis (VED) than in the stratum corneum. The skin penetration enhancing effect of chitosan and its derivatives has been reported in some studies. It has been postulated in previous studies that chitosan, based on its cationic nature, has the ability to open the tight junctions between the stratum corneum cells which carry a negative charge [36,41]. Thus, it increases the intercellular spaces and detach/ loosen the corneocytes by disordering the lipid bilayer structure [36]. This penetration enhancement effect permitted RSV to cross the

Table 1

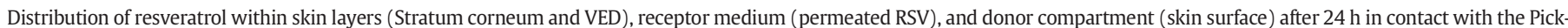

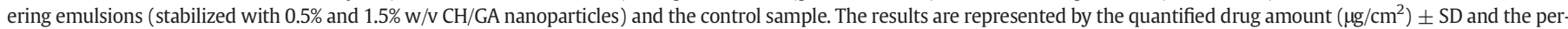
centage relative to the total applied dose.

\begin{tabular}{|c|c|c|c|c|c|c|}
\hline Formulation & Total applied dose & Stratum corneum (SC) & Viable epidermis and dermis (VED) & Permeated RSV (24 h) & Skin surface $^{a}$ & Mass recovery \\
\hline $\begin{array}{l}0.5 \% \mathrm{w} / \mathrm{v} \text { PE } \\
\mu \mathrm{g} / \mathrm{cm}^{2} \\
\% \text { of total applied dose }\end{array}$ & $468.75 \pm 0.00$ & $\begin{array}{l}3.98 \pm 0.50 \\
0.85\end{array}$ & $\begin{array}{l}50.41 \\
10.75\end{array}$ & $\begin{array}{l}10.30 \pm 1.10 \\
2.20\end{array}$ & $\begin{array}{l}341.23 \pm 196.46 \\
72.80\end{array}$ & $\begin{array}{l}405.92 \pm 180.40 \\
86.60\end{array}$ \\
\hline $\begin{array}{l}1.5 \% \mathrm{w} / \mathrm{v} \mathrm{PE} \\
\mu \mathrm{g} / \mathrm{cm}^{2} \\
\% \text { of total applied dose }\end{array}$ & $468.75 \pm 0.00$ & $\begin{array}{l}4.51 \pm 0.55 \\
0.96\end{array}$ & $\begin{array}{l}46.24 \pm 18.51 \\
9.86\end{array}$ & $\begin{array}{l}14.79 \pm 5.78 \\
3.16\end{array}$ & $\begin{array}{l}444.66 \pm 22.08 \\
94.86\end{array}$ & $\begin{array}{l}510.21 \pm 35.34 \\
108.84\end{array}$ \\
\hline $\begin{array}{l}\text { Control (RSV solution) } \\
\mu \mathrm{g} / \mathrm{cm}^{2} \\
\% \text { of total applied dose }\end{array}$ & $489.64 \pm 36.17$ & $\begin{array}{l}0 \\
0\end{array}$ & $\begin{array}{l}14.02 \pm 2.01 \\
2.86\end{array}$ & $\begin{array}{l}56.88 \pm 27.29 \\
11.62\end{array}$ & $\begin{array}{l}398.74 \pm 8.01 \\
81.44\end{array}$ & $\begin{array}{l}469.64 \pm 32.26 \\
95.92\end{array}$ \\
\hline
\end{tabular}

\footnotetext{
a Represents the amount of RSV quantified on the skin surface and the residual sample in the donor compartment.
} 


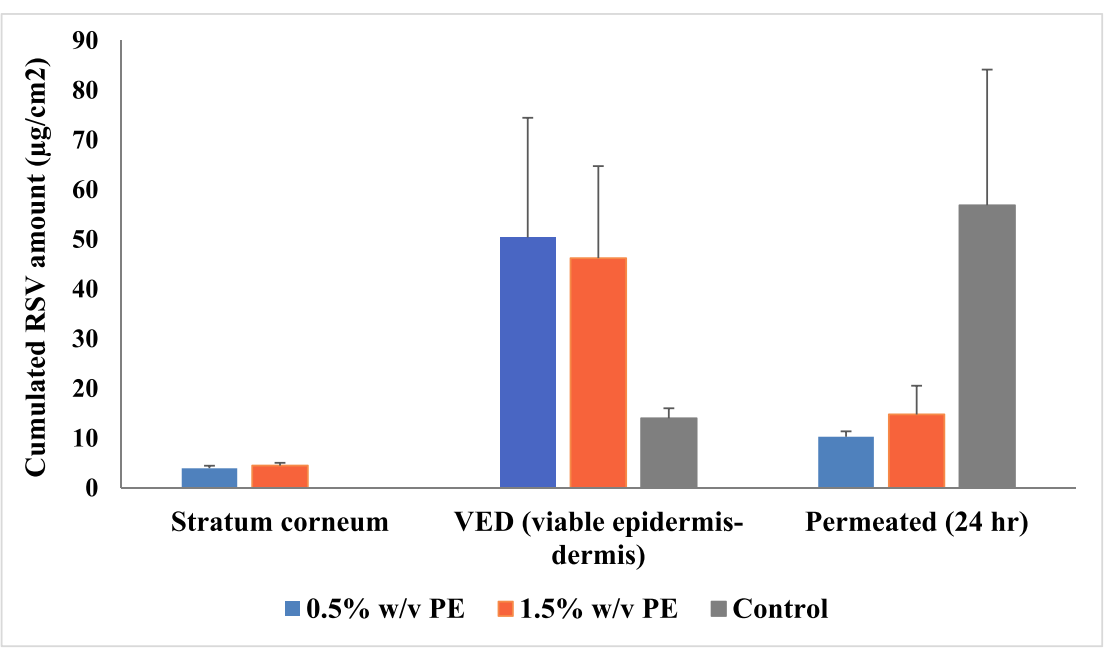

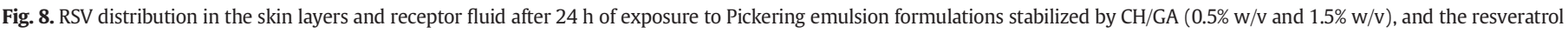
control solution. Values are represented as mean $\pm \operatorname{SD}(n=3)$. Note: No RSV was detected in the stratum corneum for the control solution.

stratum corneum causing its accumulation in the viable epidermis and dermis. At the same time, Pickering formulations acted as a barrier against the transfer and diffusion of RSV to the receptor chamber, thus successfully achieving the topical delivery of RSV.

The findings of the present work demonstrate the important role of $\mathrm{CH}$ in the produced nanoparticles and derived emulsions in enhancing the skin delivery of RSV. As such, it is worth noting that the presence of $\mathrm{GA}$ in $\mathrm{CH} / \mathrm{GA}$ nanoparticles is crucial in tuning the wettability of the produced nanoparticles, and hence improving the stability of the developed Pickering emulsions [23].

The overall mass recovery \% was quite satisfactory for a highly photosensitive compound like resveratrol. It was observed that $>85 \%$ of the applied dose of resveratrol was recovered. This is in agreement with the OECD guidelines which states that a mass recovery of $100 \pm 20 \%$ is acceptable for chemically unstable substances [27], which validates the obtained results.

\subsection{Determination of skin retention by CLSM}

CLSM was used to visualize the skin retention through Nile Red. Using fluorescent dyes as a substitute for the active agents and drugs to study the permeation of new formulations is a common technique applied to study topical applications [7,29]. Nile Red is a lipophilic dye with a high octanol-water partition coefficient $\left(\log \mathrm{P}_{\mathrm{o} / \mathrm{w}}>3\right)$ [29].
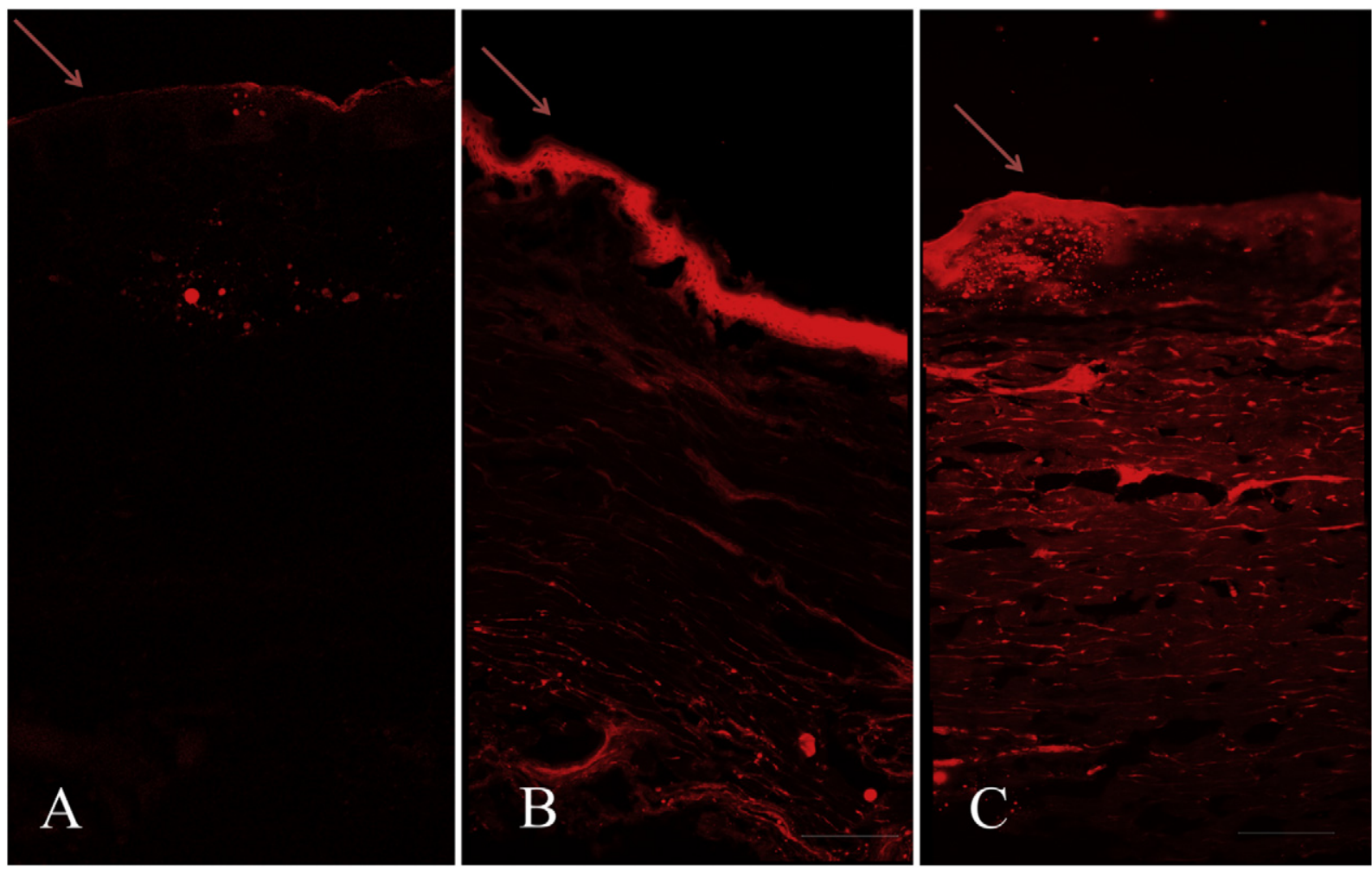

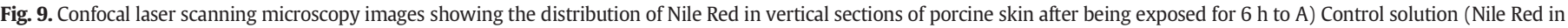

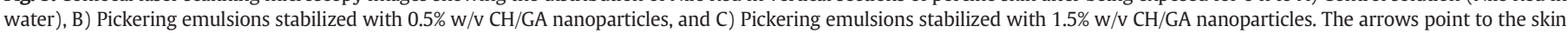
surface (the stratum corneum side). Scale bar corresponds to $100 \mu \mathrm{m}$. 


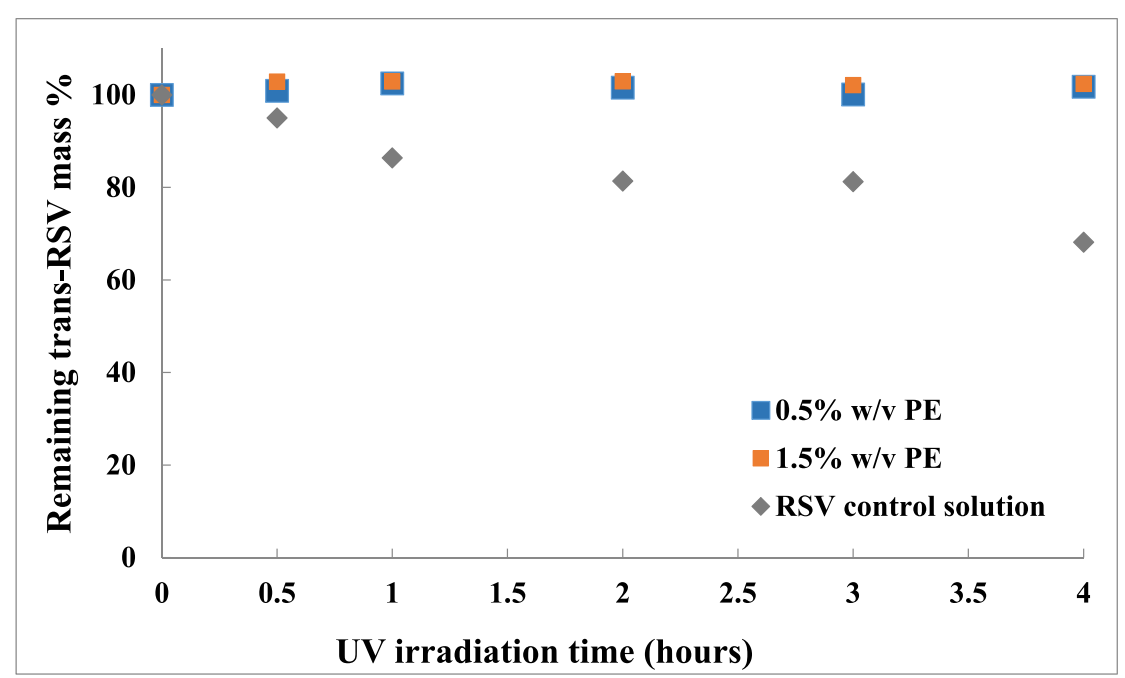

Fig. 10. Percentages of remaining RSV mass in Pickering emulsions stabilized by $0.5 \%$ and $1.5 \% \mathrm{w} / \mathrm{v} \mathrm{CH} / \mathrm{GA}$ nanoparticles, and in RSV control solution upon exposure to UV radiation.

Therefore, it was chosen in this study to substitute RSV $\left(\log \mathrm{P}_{\mathrm{o} / \mathrm{w}}\right.$ of 3.1$)$ [14], and visualize its skin retention and distribution by the produced Pickering formulations.

The studied Picketing emulsions (stabilized by $0.5 \%$ and $1.5 \% \mathrm{w} / \mathrm{v}$ $\mathrm{CH} / \mathrm{GA}$ nanoparticles) were representative of low and high nanoparticles concentration. It must be highlighted that according to previous studies of our group, lower concentrations did not allow the preparation of stable emulsions [23], and higher concentrations will give rise to smaller droplet size, and potentiate skin permeation which was not the objective of this work.

Fig. 9 shows CLSM images of cross-sectioned skin treated with Nile Red-loaded Pickering emulsions stabilized by $0.5 \% \mathrm{w} / \mathrm{v}$ and $1.5 \% \mathrm{w} / \mathrm{v}$ $\mathrm{CH} / \mathrm{GA}$ nanoparticles and the control solution containing Nile Red. It can be observed that the fluorescence intensity in the skin sections treated with the Pickering formulations (Fig. 9B and C) is higher than the one treated with the control sample, which indicates higher skin penetration and deposition of the lipophilic dye from the Pickering formulations. These results are in agreement with the overall retained RSV mass values obtained in Table 1, which shows that the Pickering formulations led to greater cutaneous deposition of the lipophilic active agent. The images also show that the Pickering formulation stabilized by $0.5 \%$ $\mathrm{w} / \mathrm{v} \mathrm{CH} / \mathrm{GA}$ nanoparticles has higher fluorescence intensity in the viable epidermis layer than in the dermis (Fig. 9B), while for the formulation stabilized by $1.5 \% \mathrm{w} / \mathrm{v}$ nanoparticles (Fig. $9 \mathrm{C}$ ) the fluorescence in the viable epidermis was less intense. However, it can be observed that the fluorescence in the dermis for the formulation stabilized with $1.5 \% \mathrm{w} /$ $\mathrm{v}$ nanoparticles is more intense (Fig. 9C) than that for the formulation stabilized by $0.5 \% \mathrm{w} / \mathrm{v}$. The images again confirm that the presence of greater number of the cationic $\mathrm{CH} / \mathrm{GA}$ nanoparticles enhances the penetration of the active agent (Nile Red in this case) through the stratum corneum, and subsequently its deposition in deeper skin layers.

\subsection{Photostability}

Trans-resveratrol is known to have strong antioxidant activity. However, being unstable, it converts to the less bioactive isomer cisresveratrol upon exposure to UV radiation [42]. Therefore, it is important to maintain its photostability during storage, and subsequently during its application on the skin. The photodegradation profiles (Fig. 10) show that $68.15 \%$ of RSV in the control solution was lost after $4 \mathrm{~h}$ of UV exposure, whereas the amount of RSV in the Pickering emulsion formulations remained unchanged. This protection from degradation is mainly attributed to the polymeric nanoparticles that surround the emulsion droplets and provide a shielding effect and physical barrier against the destructive UV radiation. Additionally, the presence of olive oil at high concentration $(\varphi=0.6)$ in the developed Pickering emulsions helped in the photostabilzation of resveratrol. It has been reported that the nanoparticles present at the droplets surface in Pickering emulsions scatter and attenuate the incident UV radiation leading to the photostabilization of trans-resveratrol [26]. Olive oil and other vegetable oils have been reported to efficiently protect photosensitive compounds from photodegradation in oil solutions and in cosmetic creams [43]. The results in the present work show that Pickering emulsion formulations stabilized with $0.5 \%$ and $1.5 \% \mathrm{w} / \mathrm{v} \mathrm{CH} / \mathrm{GA}$ nanoparticles have protected resveratrol against UV degradation after $4 \mathrm{~h}$ of exposure.

\section{Conclusions}

Chitosan/gum Arabic Pickering emulsions were successfully used as biodegradable surfactant-free vehicles for the skin application of transresveratrol. The skin permeation results of resveratrol from the developed Pickering emulsions have shown that resveratrol was retained in higher levels in the viable epidermis and dermis, which is advantageous to give the required cosmetic effect without the need of using chemical penetration enhancers. Photostability tests have shown that Pickering formulations protected trans-resveratrol against degradation by UV radiation. To our knowledge, this is the first study that investigated the skin uptake of resveratrol from Pickering emulsions. The results obtained in this work suggest that the produced chitosan/gum Arabic nanoparticles-stabilized Pickering emulsions enhanced the cutaneous delivery of resveratrol, thus they demonstrate a potential contribution towards green and sustainable cosmetics.

\section{CRediT authorship contribution statement}

Asma Sharkawy: Conceptualization, Methodology, Investigation, Writing - original draft. Filipa M. Casimiro: Methodology, Investigation. Maria Filomena Barreiro: Supervision, Writing - review \& editing. Alírio E. Rodrigues: Supervision, Writing - review \& editing.

\section{Acknowledgments}

This work was supported by Associate Laboratory LSRE-LCM - UID/ EQU/50020/2019 - funded by national funds through FCT/MCTES (PIDDAC), and Foundation for Science and Technology (FCT, Portugal); and CIMO (UID/AGR/00690/2019) through FEDER under Program PT2020. The authors acknowledge the technical support provided by the Instituto de Investigação e Inovação (i3s) and CEMUP, University 
of Porto. The authors are thankful to Dr. Patricia Costa for providing the skin samples, and Tasneem Sharkawi for language editing. Asma Sharkawy acknowledges the financial support from the FCT doctoral grant (PD/BD/135085/2017).

\section{References}

[1] M. Philippe, B. Didillon, L. Gilbert, Industrial commitment to green and sustainable chemistry: using renewable materials \& developing eco-friendly processes and ingredients in cosmetics, Green Chem. 14 (2012) 952-956, https://doi.org/10.1039/ c2gc16341a.

[2] G. Liobikienė, J. Bernatonienè, Why determinants of green purchase cannot be treated equally? The case of green cosmetics: literature review, J. Clean. Prod. 162 (2017) 109-120, https://doi.org/10.1016/j.jclepro.2017.05.204.

[3] Y. Chevalier, M.-A. Bolzinger, Emulsions stabilized with solid nanoparticles: Pickering emulsions, Colloids Surfaces A Physicochem. Eng. Asp. 439 (2013) 23-34, https://doi.org/10.1016/J.COLSURFA.2013.02.054.

[4] A. Seweryn, Interactions between surfactants and the skin - theory and practice, Adv. Colloid Interf. Sci. 256 (2018) 242-255, https://doi.org/10.1016/J.CIS.2018.04. 002.

[5] J. Marto, A. Ascenso, S. Simoes, A.J. Almeida, H.M. Ribeiro, Pickering emulsions: challenges and opportunities in topical delivery, Expert Opin. Drug Deliv. 13 (2016) 1093-1107, https://doi.org/10.1080/17425247.2016.1182489.

[6] D. Marku, M. Wahlgren, M. Rayner, M. Sjöö, A. Timgren, Characterization of starch Pickering emulsions for potential applications in topical formulations, Int. J. Pharm. 428 (2012) 1-7, https://doi.org/10.1016/J.JJPHARM.2012.01.031.

[7] F. Laredj-Bourezg, M.-A. Bolzinger, J. Pelletier, Y. Chevalier, Pickering emulsions stabilized by biodegradable block copolymer micelles for controlled topical drug delivery, Int. J. Pharm. 531 (2017) 134-142, https://doi.org/10.1016/J.JJPHARM.2017.08. 065 .

[8] J. Marto, A. Duarte, S. Simões, L.M. Gonçalves, L.F. Gouveia, A.J. Almeida, H.M. Ribeiro, Starch-based Pickering emulsions as platforms for topical antibiotic delivery: in vitro and in vivo studies, Polymers (Basel) 11 (2019) https://doi.org/10.3390/ polym11010108.

[9] I. Aranaz, N. Acosta, C. Civera, B. Elorza, J. Mingo, C. Castro, M. de los L. Gandía, A.H. Caballero, Cosmetics and cosmeceutical applications of chitin, chitosan and their derivatives, Polymers (Basel) 10 (2018) https://doi.org/10.3390/polym10020213.

[10] C.R. Afonso, R.S. Hirano, A.L. Gaspar, E.G.L. Chagas, R.A. Carvalho, F.V. Silva, G.R Leonardi, P.S. Lopes, C.F. Silva, C.M.P. Yoshida, Biodegradable antioxidant chitosan films useful as an anti-aging skin mask, Int. J. Biol. Macromol. 132 (2019) 1262-1273, https://doi.org/10.1016/J.IJBIOMAC.2019.04.052.

[11] H. Trommer, R.H.H. Neubert, The examination of polysaccharides as potential antioxidative compounds for topical administration using a lipid model system, Int. J. Pharm. 298 (2005) 153-163, https://doi.org/10.1016/J.JJPHARM.2005.04.024.

[12] VS. Chedea, S.I Vicas, C Sticozzi, F. Pessina, M. Frosini, E Maioli, G. Valacchi, Resveratrol: from diet to topical usage, Food Funct. 8 (2017) 3879-3892, https://doi.org/ 10.1039/c7fo01086a.

[13] N. Pannu, A. Bhatnagar, Resveratrol: from enhanced biosynthesis and bioavailability to multitargeting chronic diseases, Biomed. Pharmacother. 109 (2019) 2237-2251, https://doi.org/10.1016/J.BIOPHA.2018.11.075.

[14] N. Summerlin, E. Soo, S. Thakur, Z. Qu, S. Jambhrunkar, A. Popat, Resveratrol nanoformulations: challenges and opportunities, Int. J. Pharm. 479 (2015) 282-290, https://doi.org/10.1016/J.IJPHARM.2015.01.003.

[15] E.D. Lephart, J.M. Sommerfeldt, M.B. Andrus, Resveratrol: influences on gene expression in human skin, J. Funct. Foods 10 (2014) 377-384, https://doi.org/10.1016/J.JFF. 2014.07.017.

[16] J. Chen, N. Wei, M. Lopez-Garcia, D. Ambrose, J. Lee, C. Annelin, T. Peterson, Development and evaluation of resveratrol, vitamin $\mathrm{E}$, and epigallocatechin gallate loaded lipid nanoparticles for skin care applications, Eur. J. Pharm. Biopharm. 117 (2017) 286-291, https://doi.org/10.1016/J.EJPB.2017.04.008.

[17] S.N. Park, N.R. Jo, S.H. Jeon, Chitosan-coated liposomes for enhanced skin permeation of resveratrol, J. Ind. Eng. Chem. 20 (2014) 1481-1485, https://doi.org/10 1016/J.JIEC.2013.07.035

[18] O.V.Zillich, U. Schweiggert-Weisz, K. Hasenkopf, P. Eisner, M. Kerscher, Release and in vitro skin permeation of polyphenols from cosmetic emulsions, Int. J. Cosmet. Sci. 35 (2013) 491-501, https://doi.org/10.1111/ics.12072.

[19] X. Lu, C. Li, Q. Huang, Combining in vitro digestion model with cell culture model: assessment of encapsulation and delivery of curcumin in milled starch particle stabilized Pickering emulsions, Int. J. Biol. Macromol. 139 (2019) 917-924, https://doi. org/10.1016/J.IJBIOMAC.2019.08.078.

[20] M.R. Lima Cardial, H.C.B. Paula, R.B.C. da Silva, J.F. da Silva Barros, A.R. Richter, F.M. Sombra, R.C.M. de Paula, Pickering emulsions stabilized with cashew gum nanoparticles as indomethacin carrier, Int. J. Biol. Macromol. 132 (2019) 534-540, https:// doi.org/10.1016/J.IJBIOMAC.2019.03.198.

[21] M. Matos, A. Laca, F. Rea, O. Iglesias, M. Rayner, G. Gutiérrez, O/W emulsions stabilized by OSA-modified starch granules versus non-ionic surfactant: stability, rheological behaviour and resveratrol encapsulation, J. Food Eng. 222 (2018) 207-217, https://doi.org/10.1016/J.JFOODENG.2017.11.009.

[22] Y. Zhang, X. Xu, Q. Wang, H. Zhang, A. Qian, T. Liu, Q. Xia, Preparation and characterization of colloidal particles synergistic with emulsifier stabilizing Pickering emulsion, Integr. Ferroelectr. 180 (2017) 24-36, https://doi.org/10.1080/10584587. 2017.1336420

[23] A. Sharkawy, M.F. Barreiro, A.E. Rodrigues, Preparation of chitosan/gum Arabic nanoparticles and their use as novel stabilizers in oil/water Pickering emulsions, Carbohydr. Polym. 224 (2019), 115190. https://doi.org/10.1016/J.CARBPOL.2019. 115190.

[24] P. Shao, J. Feng, P. Sun, C. Ritzoulis, Improved emulsion stability and resveratrol encapsulation by whey protein/gum arabic interaction at oil-water interface, Int. J. Biol. Macromol. 133 (2019) 466-472, https://doi.org/10.1016/J.JBIOMAC.2019.04.126.

[25] S. Scalia, V. Trotta, V. Iannuccelli, A. Bianchi, Enhancement of in vivo human skin penetration of resveratrol by chitosan-coated lipid microparticles, Colloids Surfaces B Biointerfaces 135 (2015) 42-49, https://doi.org/10.1016/J.COLSURFB.2015.07.043.

[26] L. Dai, Y. Li, F. Kong, K. Liu, C. Si, Y. Ni, Lignin-based nanoparticles stabilized Pickering emulsion for stability improvement and thermal-controlled release of transresveratrol, ACS Sustain. Chem. Eng. 7 (2019) 13497-13504, https://doi.org/10. 1021/acssuschemeng.9b02966.

[27] OECD, Guidance Document for the Conduct of Skin Absorption Studies, OECD Series on Testing and Assessment, No. 28, , OECD Publishing, Paris, 2004 https://doi.org/10. 1787/9789264078796-en Paris. (doi:10.1787/9789264078796-en).

[28] Y. Zhang, B.C. Sil, C.-P. Kung, J. Hadgraft, M. Heinrich, B. Sinko, M.E. Lane, Characterization and topical delivery of phenylethyl resorcinol, Int. J. Cosmet. Sci. 41 (2019) 479-488, https://doi.org/10.1111/ics.12565.

[29] J.-W. Hu, M.-W. Yen, A.-J. Wang, I.-M. Chu, Effect of oil structure on cyclodextrinbased Pickering emulsions for bupivacaine topical application, Colloids Surfaces B Biointerfaces 161 (2018) 51-58, https://doi.org/10.1016/J.COLSURFB.2017.10.001.

[30] M.A. Khan, C. Yue, Z. Fang, S. Hu, H. Cheng, A.M. Bakry, L. Liang, Alginate/chitosancoated zein nanoparticles for the delivery of resveratrol, J. Food Eng. 258 (2019) 45-53, https://doi.org/10.1016/J.JFOODENG.2019.04.010.

[31] J. Li, X. Xu, Z. Chen, T. Wang, Z. Lu, W. Hu, L. Wang, Zein/gum Arabic nanoparticlestabilized Pickering emulsion with thymol as an antibacterial delivery system, Carbohydr. Polym. 200 (2018) 416-426, https://doi.org/10.1016/J.CARBPOL.2018. 08.025 .

[32] Z. Wei, Q. Huang, Edible Pickering emulsions stabilized by ovotransferrin-gum arabic particles, Food Hydrocoll. 89 (2019) 590-601, https://doi.org/10.1016/J. FOODHYD.2018.11.037.

[33] Q. Zhu, H. Lu, J. Zhu, M. Zhang, L. Yin, Development and characterization of Pickering emulsion stabilized by zein/corn fiber gum (CFG) complex colloidal particles, Food Hydrocoll. 91 (2019) 204-213, https://doi.org/10.1016/J.FOODHYD.2019.01.029.

[34] X. Li, K. Li, Y. Shen, F. Niu, Y. Fu, Influence of pure gum on the physicochemical properties of whey protein isolate stabilized oil-in-water emulsions, Colloids Surfaces A Physicochem. Eng. Asp. 504 (2016) 442-448, https://doi.org/10.1016/J.COLSURFA. 2016.05.046.

[35] Y. Jiang, C. Zhang, J. Yuan, Y. Wu, F. Li, D. Li, Q. Huang, Effects of pectin polydispersity on zein/pectin composite nanoparticles (ZAPs) as high internal-phase Pickering emulsion stabilizers, Carbohydr. Polym. 219 (2019) 77-86, https://doi.org/10. 1016/J.CARBPOL.2019.05.025.

[36] B. Sapra, S. Jain, A.K. Tiwary, Transdermal delivery of carvedilol containing glycyrrhizin and chitosan as permeation enhancers: biochemical, biophysical, microscopic and pharmacodynamic evaluation, Drug Deliv 15 (2008) 443-454, https://doi.org/10.1080/10717540802327047.

[37] R.H. Müller, M. Radtke, S.A. Wissing, Solid lipid nanoparticles (SLN) and nanostructured lipid carriers (NLC) in cosmetic and dermatological preparations, Adv. Drug Deliv. Rev. 54 (2002) S131-S155, https://doi.org/10.1016/S0169-409X(02)00118-7.

[38] M. Kong, X.G. Chen, D.K. Kweon, H.J. Park, Investigations on skin permeation of hyaluronic acid based nanoemulsion as transdermal carrier, Carbohydr. Polym. 86 (2011) 837-843, https://doi.org/10.1016/J.CARBPOL.2011.05.027.

[39] J. Frelichowska, M.-A. Bolzinger, J.-P. Valour, H. Mouaziz, J. Pelletier, Y. Chevalier, Pickering w/o emulsions: drug release and topical delivery, Int. J. Pharm. 368 (2009) 7-15, https://doi.org/10.1016/J.IJPHARM.2008.09.057.

[40] J. Frelichowska, M.A. Bolzinger, J. Pelletier, J.P. Valour, Y. Chevalier, Topical delivery of lipophilic drugs from o/w Pickering emulsions, Int. J. Pharm. 371 (2009) 56-63, https://doi.org/10.1016/j.ijpharm.2008.12.017.

[41] Y. Chen, M. Wang, L. Fang, Biomaterials as novel penetration enhancers for transdermal and dermal drug delivery systems, Drug Deliv 20 (2013) 199-209, https://doi. org/10.3109/10717544.2013.801533.

[42] C.G. Silva, J. Monteiro, R.R.N. Marques, A.M.T. Silva, C. Martínez, M. Canle L, J.L. Faria, Photochemical and photocatalytic degradation of trans-resveratrol, Photochem. Photobiol. Sci. 12 (2013) 638-644, https://doi.org/10.1039/c2pp25239b.

[43] M. Brisaert, J.A. Plaizier-Vercammen, Investigation on the photostability of tretinoin in creams, Int. J. Pharm. 334 (2007) 56-61, https://doi.org/10.1016/JIJPHARM.2006. 10.023 . 